common the situation is not entirely one of gloom, since at review about $70 \%$ of the patients in whom the disease had recurred were in reasonable health.

The cause of Crohn's disease remains unknown so it is not surprising that results of both medical and surgical treatment are far from satisfactory. There seems little doubt that advances in therapy should follow further knowledge of the cause, and recent studies 1213 which suggest that there might be a transmissable agent in tissue obtained from patients with Crohn's disease open up interesting prospects for the future.

\footnotetext{
1 de Dombal, F. T., Burton, I., and Goligher, J. C., British fourral of

Surgery, 1971, 58, 805.
2 Dyer, N. H., and Dawson, A. M., British fournal of Surgery, 1971, 60, 134.

3 Williams, J. A., Fielding, J. F., and Cooke, W. T., Gut, 1972, 13, 973.

4 Frank, J. D., and Shorey, B. A., Gut, 1973, 14, 120.

5 Localio, S. A., Colcock, B. P., Klein, S., and Rodkey, G. V., American fournal of Gastroenterology, $1973,60,213$.

- Nugent, F. W., Veidenheimer, M. C., Meissner, W. A., and Haggitt, R. C., Gastroenterology, 1973, 65, 398 .

7 Ritchie, J. K., and Lockhart-Mummery, H. E., Gut. 1973, 14, 263.

8 de Dombal, F. T., Burton, I., and Holigher, J. C., Gut, 1971, 12, 519. liams, J. A., Gut, 1973, $14,818$.

10 Burman, J. H., Cooke, W. T., and Williams, J. A., Gut, 1971, 12, 432.

11 Baker, W. N. W., Gut, 1971, 12, 427.

12 Mitchell, D. N., and Rees, R. J. W., Proceedings of the Royal Society of Medicine, 1971, 64, 944.

18 Cave, D. R., Mitchell, D. N., Kane, S. P., and Brooke, B. N., Lancet, $1973,2,1120$.
}

\section{Irresponsible Poisoning}

About a third of a million children are poisoned each year in Britain. Prescribed drugs are responsible for a high proportion of these cases-and one of increasing importance. We still have ferrous sulphate tablets that look like Smarties, and we regularly prescribe more than lethal total amounts of barbiturates. The situation is disturbing and, to outside observers, seems to be handled with amazing irresponsibility; indeed our attitude to tricyclic antidepressants seems to have a Kafka-like flavour.

The tricyclic antidepressant drug imipramine was introduced with immediate success in the late 1950s. One of the first fatal cases of poisoning was reported ${ }^{1}$ in Melbourne in 1960 - a child who had taken his mother's Tofranil tablets. The report ends with the comment, "The father of this boy was quick to state the obvious point that the tablets were a pretty pink and sugar-coated. He felt sure that, but for these characteristics, the child would not have taken more than a few of them. Drugs dangerous to children should be made distasteful and unattractive." Ten years later in that same city Brown, Dwyer, and Stocks ${ }^{2}$ showed that admissions for poisoning with tricyclic antidepressant drugs had overtaken those for overdosage of barbiturates.

Matters became worse when these same drugs were (inevitably) introduced as a treatment for enuresis. The possible dangers were pointed out ${ }^{3}$ in the $B . M . \mathcal{F}$., but only last week (p. 261) we carried a report of 60 children admitted between January 1966 and July 1973 with poisoning with tricyclic antidepressants; of these over half had been prescribed for enuresis. Antidepressant tablets are still pink or brown sugar-coated sweets.

Perhaps the experience in Glasgow is not reflected in centres where the treatment of enuresis excludes this drug, but even in such centres poisoning with tricyclics seems an increasingly important group in paediatric departments and resuscitation wards. The clinical control of tricyclic poisoning is not simple. There is no clear correlation between the amount of drug taken and the extent and type of symptoms. The analysis of tissue fluids is qualitative and not quantitative and there is no freely available antidote.

A review ${ }^{4}$ of published work on tricyclic poisoning in children by Steel, O'Duffy, and Brown in 1967 set out the symptoms of the condition and its management, and the more recent experience of Drs. K. M. Goel and R. A. Shanks largely supports its findings. Toxic symptoms in the children are many and variable. ${ }^{5}$ Vomiting is not common, but there are usually behaviour disturbances with restlessness, ataxia, convulsions, and coma; the most usual picture is a combination of restlessness and drowsiness. There is frequently a sinus tachycardia and other electrocardiographic abnormalities. The lethal features lie in the effects of the drug on the respiratory centre and heart, and, as Rasmussen pointed ${ }^{6}$ out in 1965, barbiturates are potential respiratory depressants and should not be used to control convulsions. Paraldehyde was recommended by Steel et al., and Goel and Shanks used diazepam. The toxic effects are enhanced by any increase in the cardiac workload, so it is important to keep these children in an as unstimulated and restful state as possible. The highest mortality is in the first 24 hours, and the prognosis improves considerably following this. Even if the child ceases to show symptoms, however, he should be maintained for at least three days with E.C.G. monitoring before discharge. Similarly, all children with suspicion of poisoning with tricyclics, whether symptomatic or not, should have E.C.G. monitoring for 24 hours before discharge.

These cases of poisoning are preventable. If every parent kept medicines locked away from children, and drugs were dispensed in non-lethal amounts, all would be well. The bathroom and kitchen cabinets of this country contain large quantities of unused tablets and medicines, many potentially lethal to the infant in the house. In one northern industrial city it was estimated that there are one million medically prescribed tablets unused each year. A publicity campaign carried out by the Health Education Officer brought in 650,000 tablets in two weeks. ${ }^{7}$

The situation with tricyclics is more difficult than with many drugs, since they are given for chronic states in adults and children and thus tend to be dispensed in large amounts. Patients who need these drugs tend to be less than usually reliable and stable. Attempts have been made to design drug containers that are difficult for a child to open, and the British Standards Institute has recently produced two drafts on the design of reclosable and non-reclosable containers for possible use with children. ${ }^{8}{ }^{9}$ While this may help a little, it is not the right answer-most children are at least as resourceful as their parents.

The question of giving tricyclics to children with enuresis should be very seriously reconsidered. There has been a great variety in fashions in the treatment of this condition, and the evidence for the beneficial effect of tricyclics is by no means convincing. Can it really be justified to use a potentially dangerous drug in the treatment of a self-limiting, nonfatal disorder, particularly if the efficacy of the drug in the treatment is not certain?

\footnotetext{
1 Noack, C. H., Medical fournal of Australia, 1960, 2, 182.

Brown, T. C. K., Dwyer, M. E., and Stocks, J. G., Medical fournal of Australia, 1971, 2, 69.

${ }^{3}$ British Medical fournal, 1973, 2, 69.

Steel, C. M., O'Duffy, J., and Brown, S. S., British Medical fournal, 1967, 3,663 .

5 Illingworth, R. S., Treatment of the Child at Home. A Guide for the Family Doctor. Oxford, Blackwell, 1972.

6 Rasmussen, J., Lancet, 1965, 2, 850.
} 
${ }^{7}$ Rowntree, T. St. D., Interim Report: Sheffield Home Safety. Sheffield Home Safety Committee, 1973.

Resistance of Pharmaceutical Packages to Opening by Children, Part I. Reclosable Containers. London, British Standards Institute, 1973.

Resistance of Pharmaceutical Packages to Opening by Children, Part II. Non-reclosable Containers. London, British Standards Institute, 1973.

\section{Mental Side Effects of Pentazocine}

As clinical experience of the use of pentazocine has accumulated occasional unpleasant nalorphine-like perceptive effects have been reported, particularly after parenteral administration. ${ }^{1-3}$ These include visual and auditory hallucinations, dreams, delusions, euphoria, dysphoria, feelings of depersonalization, panic, and abnormal thoughts. Further evidence for the occurrence of central nervous system disturbances now comes from a prospective open study reported this week by the Medicines Evaluation and Monitoring Group (p. 305). However, the incidence of such reactions in hospital patients receiving other analgesic drugs is unknown, and prospective double-blind studies with patients matched for age, associated disease, and dose of drug are ideally needed for accurate evaluation of the frequency of these perceptual disturbances. One aspect of the problem of adverse drug reactions reemphasized by the study is the low level of voluntary reporting -only 1 of the 18 cases detected had been reported to the Committee on Safety of Medicines.

The current preparation of pentazocine is a racemic mixture, and both its analgesic and common adverse actions have been attributed to the laevo isomer, ${ }^{4}$ whereas the psychotomimetic effects may be associated with the dextro form. ${ }^{5}$ The principal unwanted effects are sedation, sweating, dizziness, and lightheadedness. Nausea may occur, but vomiting is less frequent than after the administration of morphine. As with all narcotic drugs, caution is required when prescribing for patients with respiratory insufficiency, head injury, or convulsive states. In patients with hypertension caution is required as the blood pressure may rise. ${ }^{6}$ In the management of acute myocardial infarction complicated by hypotension pentazocine may have an advantage over other opiates such as diamorphine, since the blood pressure does not commonly fall, ${ }^{7}$ though when high intravenous doses are given there may be a marked rise in pulmonary artery pressure. ${ }^{8}$

Pentazocine is largely metabolized by the liver-up to $30 \%$ is excreted as glucuronide conjugates and less than $13 \%$ appears unchanged in the urine. 10 The unmetabolized fraction is thought to be the active analgesic principle, so that a lower dose may be necessary in patients with hepatic insufficiency. The analgesic effects correlate with plasma levels, and high plasma levels have been associated with more side effects. ${ }^{11}$ In the treatment of overdosage the drug of choice is naloxone, a pure narcotic antagonist, but it is not yet widely available.

In clinical practice pentazocine is mainly used for the relief of moderate to severe pain. It has no anti-inflammatory or antipyretic activity. It is well absorbed when taken by mouth, but the total analgesic effect is only one-third of that after injection. ${ }^{12}$ A rule-of-thumb guide is that $50 \mathrm{mg}$ of oral pentazocine is approximately equivalent to $60 \mathrm{mg}$ of codeine. Frequent administration is necessary, and the recommended dose is $25-100 \mathrm{mg}$ every three to four hours. After parenteral administration the onset of action is similar to morphine, but the duration of action is slightly less as the half-life in plasma is only about two hours. ${ }^{10}$ The injection is irritant, and changes in the intramuscular injection site are necessary to prevent damage to subcutaneous tissues and skin. At optimum doses the analgesic efficacy is equivalent to morphine, but weight for weight $30-50 \mathrm{mg}$ of pentazocine appear to be equivalent to $10 \mathrm{mg}$ of morphine ${ }^{4}$ or $75-100 \mathrm{mg}$ of pethidine.

The risk of drug dependence is low and pentazocine remains free of narcotic controls. ${ }^{14}$ Occasional reports of dependence have appeared, ${ }^{15-17}$ particularly in patients previously dependent on other drugs. In such patients regular prescriptions of pentazocine must be carefully supervised.

In the seven years since its introduction pentazocine has confirmed much of its early promise as a potent analgesic, particularly when a risk of the dependence exists. Nevertheless for the relief of severe pain of short duration (where the risk of the development of addiction is more theoretical than real) and when other factors such as anxiety and apprehension are important, there is no substitute for the established narcotics such as diamorphine.

\footnotetext{
${ }^{1}$ Edison, G. R., New England fournal of Medicine, 1969, 281, 447.

De Nosaquo, N., Fournal of the American Medical Association, 1969, 210 , 502.

3 Paddock, R., et al., Clinical Pharmacology and Therapeutics, 1969, 10, 355. Forrest, W. H., et al., Clinical Pharmacology and Therapeutics, 1969, 10,

Jaffe, J. H., in The Pharmacological Basis of Therapsutics, 4th edn., ed. L. S. Goodman and A. Gilman. London, Macmillan, p. 269, 1970.

Keats, A. S., and Telford, J., Fournal of Pharmacology and Experimental Therapeutics, 1964, 143, 157 .

Therapeutics, 1964, 143, 157.
Scott, M. E., and Orr, R., Lancet, 1969, 1, 1065.

8 Jewitt, D. E., et al., British Medical fournal, 1970, 1, 795.

Berkowitz, B., and Way, L. E., Clinical Pharmacology and Therapeutics, $1969,10,681$

10 Berkowitz, B., et al., Clinical Pharmacology and Therapeutics, 1969, 10, 320. Burt, R. A. P., and Beckett, A. H., British fournal of Anaesthesia, 1971, 43, 427.

12 Bezver, W. T., et al., Clinical Pharmacology and Therapeutics, 1968, 9, 582

13 Kantor, T. G., et al., Clinical Pharmacology and Therapeutics, 1966, 7, 447

14 World Health Organization. Technical Report Series, 1970, No. 437.

15 Hart, R. H., Lancet, 1969, 2, 690.

16 Schoolar, J. C., et al., Lancet, 1969, 1, 1263.

17 Sandoval, R. G., and Wang, R. I. H., New England fournal of Medicine, $1969,280,1391$.
}

\section{Amyloid Arthropathy}

The term "amyloid arthropathy" implies a polyarthritis due to the deposition of amyloid in or around joints. ${ }^{1}$ The diagnosis can be made with absolute certainty only by finding amyloid tissue there.

The condition usually presents in middle-aged or elderly patients and can mimic rheumatoid arthritis with symmetrical swelling of joints due to invasion of the synovial tissue. It causes pain and general stiffness and, rarely, severe morning stiffness. ${ }^{2}$ Effusions may appear in the joints, particularly in the knees. The tendons and their sheaths may be affected with extensor or flexor contractures of the fingers. Para-articular swellings composed of amyloid and swellings of muscles may arise, usually associated with profound weakness. Nodules composed of amyloid can be seen along the forearm resembling rheumatoid nodules, while nodules may be widespread in the skin. ${ }^{2}$ Para-articular swellings round the shoulders have been one of the particular features of this type of arthropathy, ${ }^{3}$ and para-articular deposition can give rise to carpal tunnel-symptoms. ${ }^{4}$ As this arthropathy is associated with primary amyloidosis, there may be other evidence of that disorder, such as enlargement of the tongue, hoarseness, dysphagia, or disease of the heart, lungs, and small blood vessels or the peripheral nerves. 